\title{
Ants Are at the First Stage of the Notion of Zero
}

\author{
Marie-Claire Cammaerts ${ }^{1} \&$ Roger Cammaerts ${ }^{2}$ \\ ${ }^{1}$ Independent Researcher, Retired from the Biology of Organisms Department, University of Brussels, Belgium \\ ${ }^{2}$ Independent Researcher, Retired from the Natural and Agricultural Environmental Studies Department (DEMNA) \\ of the Walloon Region, Belgium \\ Correspondence: Marie-Claire Cammaerts, Independent Researcher, 27, Square du Castel Fleuri, 1170 Bruxelles, \\ Belgium. Tel: 32-2-673-4969. E-mail: mtricot@ulb.ac.be; mccammaerts@gmail.com
}

Received: November 12, 2018 Accepted: December 12, $2018 \quad$ Online Published: December 18, 2019

doi:10.5539/ijb.v11n1p54 URL: https://doi.org/10.5539/ijb.v11n1p54

\begin{abstract}
The notion of zero is rarely apprehended by animals. We examined if ants possess this ability in four experiments, each time using two colonies and operant conditioning. Ants succeeded in significantly comprehending the absence of a cue, but not as well as learning an existing cue, and they soon lost their learning. Ants thus have a sensory notion of the absence of an item, but not the abstract notion of a sensu stricto mathematical zero.
\end{abstract}

Keywords: Cognition, Myrmica Sabuleti, Operant Conditioning, Training

\section{Introduction}

Many animal species can distinguish different amounts or sizes of an element, and this ability has been used in the course of numerous experiments (Pearce, 2009). On the contrary, very little information has been collected on the comprehension of the notion of zero which seems to be seldom attained and only by highly evolved species. In humans, the notion of zero is tardily acquired during life, and was also tardily acquired during the history of mankind (Michelot, 1966). A five years old child does not hesitate to write ' $0+0=2$ ', and an eight years old child may write ' $4 \times 0=4$ ', showing that they have not yet acquired the numerical notion of zero. A written symbol corresponding to our present zero appeared at first rather late in the Babylonian and Hindu civilizations. Greeks and Romans never used a symbol signifying 'zero' (Michelot, 1966).

At the most basic level, the notion of zero consists of understanding the absence or the null existence of an element. Further cognitive steps consist in locating this absence relative to different amounts, then in representing it by a symbol, and ultimately in using such a 'zero' in mathematical concepts.

We aimed to examine the comprehension of a basic notion of zero in ants, i.e. the initial stage of the successive cognitive processes leading to the abstract and symbolical notion of zero. The initial notion of zero we intended to look for is deemed to be based on a good sensorial discriminating ability, for instance on an accurate visual perception. We therefore worked on an ant whose visual perception is rather well known, i.e. Myrmica sabuleti Meinert 1861. The visual perception of species of the genus Myrmica, M. sabuleti, M. ruginodis and M. rubra, has been mainly studied in terms of their recruitment and navigation systems, two social tasks largely dependent on visual perception. Consequently, the eye morphology, subtended angle of vision, discrimination of cues' dimension, number of elements, shapes, hollow forms and orientation, colour distinction, perspective perception, and light threshold of these three species or only of M. sabuleti are rather well known (Cammaerts, 2004, 2005, 2007a, 2007b, 2008, 2012a, 2013; Cammaerts \& Cammaerts, 2009; Rachidi, Cammaerts, \& Debeir, 2008) as are the relations between their visual perception, their navigation system and habitat (Cammaerts, 2012b; Cammaerts \& Rachidi, 2009; Cammaerts, Rachidi, Beke, \& Essaadi, 2012; Cammaerts \& Cammaerts, 2014). Our knowledge of the visual perception of $M$. sabuleti is now comparable to that of other insects largely studied, i.e. bees (Srinivasan, 2010; Warrant, 2008), wasps (Warrant, 2008; Collett, 1995), and the fruit fly (Dill, Wolf, \& Heisenberg, 1993).

How can we look at $M$. sabuleti workers' potential for comprehension of a 'null existence'? In our mind, a 'sensory perception of nothing' is not the perception of a white paper with nothing drawn on it. It is the perception of the non existence of any cue. In order to link our present research to previous ones on M. sabuleti workers' visual perception and discrimination of two different cues, we conducted our present research in four steps. We started with the ants' discrimination between two and one black circles drawn on white paper, then 
with the ants' discrimination between one black circle and no circle drawn on white paper. After that, in order to avoid the ants' memorization of the black circles, we went on experimenting using another cue, i.e. a black square. We examined the ants' discrimination between one black square drawn on white paper and the absence of both a white paper and a black square, i.e. 'nothing'. Finally, we reproduced the latter experiment on not yet used colonies (i.e. naïve ones) to verify the previous results. After having related our methods and results (blindly obtained as the results obtained by other researchers on the subject), we report information on the understanding of the notion of zero by some evolved animals and make conclusions.

\section{Material and Methods}

\subsection{Collection and Maintenance of Ants}

The experiments were made on four colonies collected in September 2018 in abandoned quarries of the Aise valley (Ardenne, Belgium), the colonies A and B nesting at a site located about one kilometer more upstream than the site where a big colony, divided into colonies $\mathrm{C}$ and $\mathrm{D}$, was living. All these experimental colonies were maintained in the laboratory in two to three glass tubes half filled with water, a cotton plug separating the ants from the water. The nest tubes of each colony were set in a tray $(34 \mathrm{~cm} \times 23 \mathrm{~cm} \times 4 \mathrm{~cm})$ serving as foraging area, and the ants received pieces of Tenebrio molitor larvae (Linnaeus, 1758) three times per week, as well as sugar water permanently at their disposal in cotton plugged tubes. The ambient temperature was $c a 20^{\circ} \mathrm{C}$, the humidity $80 \%$, the lighting 330 lux while working on ants, and the electromagnetism $2 \mu \mathrm{Wm}^{2}$, these environmental conditions being optimum for the species. In the present work, the ants are often named 'nestmates' as done by researchers on social insects.

\subsection{Cues and Method Used}

We used four different cues schematized in Figure 1, upper part, as well as the absence of a cue. Each cue consisted of a stand made of strong white paper $\left(\right.$ Steinbach $\left.^{\circledR}\right)$, to which a squared piece of white paper was tied, with one black circle, two black circles, nothing or a black square drawn on it. The dimensions of all these parts of the used cues are given in Figure 1, upper part.

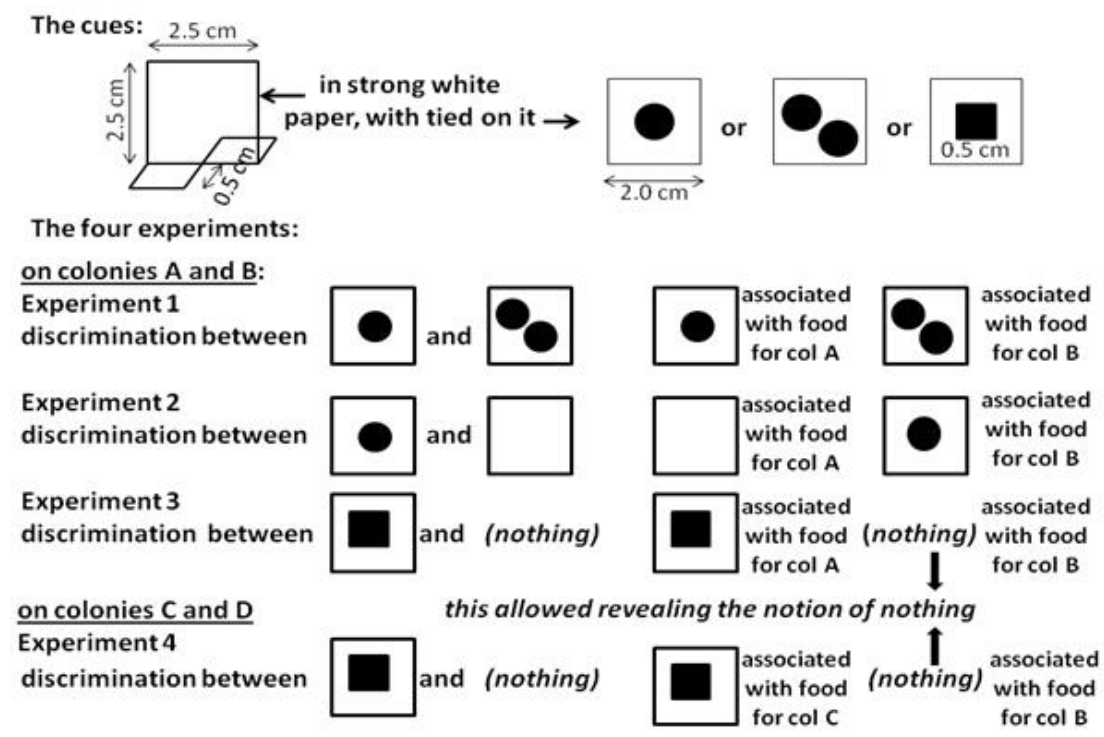

Figure 1 . The cues used and the four experiments made for examining if ants have a sensory perceptible notion of 'nothing'

The method used for examining if ants could discriminate the different used cues, including the absence of a cue, was the operant conditioning. Two different cues were deposited in the foraging area of a colony, one of them being set very near the food (meat and sugar water), the other cue being set at a distance of $12 \mathrm{~cm}$ from the food. The ants were expected to associate one kind of cue with their usual food, and to respond to that cue (to come near it) when later on tested in front of the two cues without any food. The exact experimental plan is related in the following subsection. 


\subsection{Experimental Plan}

A schematic presentation of our plan is given in Figure 1, lower part. Four experiments were made successively. During experiment 1, the cues provided to colonies A and B were one black circle and two black circles, the one black circle being associated with food for colony A and the two black circles being associated with food for colony B. During experiment 2, the cues provided to colonies A and B were one black circle and a white paper, the white paper being associated with food for colony A and the black circle being associated with food for colony B. During experiment 3, colonies A and B received, as cues, a black square and 'nothing' (= no cue), the black square being associated with food for colony A, the 'nothing' being associated with food for colony B. Experiment 4 was made to check the results of the experiment 3. It was performed without looking at the results of experiment 3, i.e. being blind to the situation. During this experiment 4 , colonies $\mathrm{C}$ and $\mathrm{D}$ received, as cues, a black square and 'nothing', the black square being associated with food for colony C, the 'nothing' being associated with food for colony D. Each time, the ants were trained until their conditioning score no longer increased, and were, during that training time period, tested, i.e. confronted with the cues received while being trained, after given time periods. After that, the cues were removed from the ants' foraging area, and the ants' loss of conditioning was examined. All this is explained in the two following sub sections.

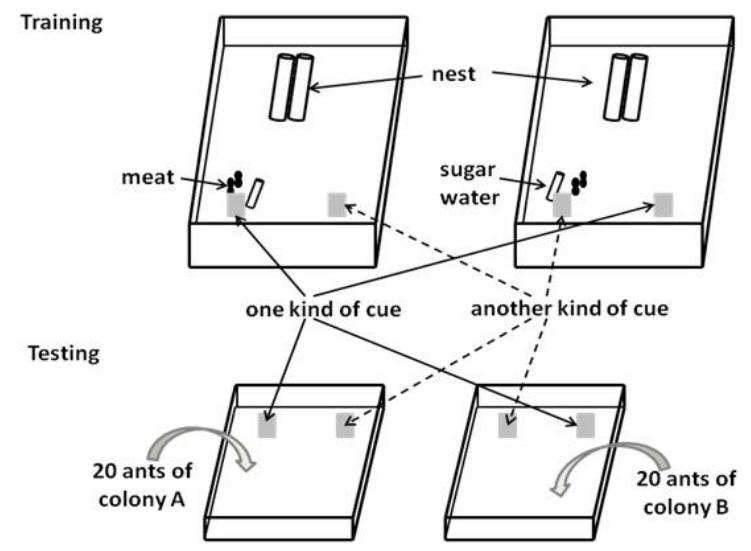

Figure 2. Experimental design used for training and testing the ants

Table 1. Experiment 1: Ants' discrimination between one and two black circles

\begin{tabular}{|c|c|c|c|c|c|c|}
\hline \multirow[b]{2}{*}{ Training } & \multicolumn{5}{|c|}{ Mean $n^{\circ}$ of ants near the cues } & \\
\hline & \multicolumn{3}{|c|}{ Colony A } & \multicolumn{3}{|c|}{ Colony B } \\
\hline Day 1 & 3.50 & & 0.75 & 3.00 & & 0.75 \\
\hline Day 2 & 6.50 & & 1.25 & 3.75 & & 0.50 \\
\hline Day 3 & 4.00 & & 0.75 & 4.25 & & 0.75 \\
\hline \multicolumn{7}{|c|}{ Cues removed } \\
\hline \multirow{3}{*}{ Testing } & \multicolumn{5}{|c|}{ Mean $n^{\circ}$ of ants near the cues and $\%$ of correct responses } & \\
\hline & \multicolumn{3}{|c|}{ Colony A } & \multirow{2}{*}{\multicolumn{2}{|c|}{ Colony B }} & \\
\hline & & & $\%$ & & & $\%$ \\
\hline 24 hours & 1.45 & 0.65 & 68.1 & 2.95 & 1.00 & 74.7 \\
\hline 48 hours & 5.15 & 1.30 & 79.8 & 4.85 & 1.50 & 76.4 \\
\hline 72 hours & 3.15 & 1.05 & 75.0 & 5.85 & 0.65 & 90.0 \\
\hline \multicolumn{7}{|c|}{ Cues removed } \\
\hline 24 hours & 1.50 & 0.30 & 83.3 & 2.65 & 0.80 & 76.8 \\
\hline 48 hours & 1.65 & 1.35 & 55.0 & 1.35 & 0.85 & 61.4 \\
\hline 72 hours & 1.15 & 1.05 & 52.3 & 0.75 & 0.85 & 46.9 \\
\hline
\end{tabular}

Each training mean corresponds to 4 counts; each testing mean corresponds to 20 counts. The ants could very well distinguish the two presented cues. Statistics are given in the text. 


\subsection{Training the Ants}

The experimental design allowing the ants' training is shown in Figure 2, upper part. Two kinds of cues were placed in the ants' foraging area, one kind near the food for one colony, the other kind near the food for the other colony. The ants present near each kind of food were counted four times per day during each training day, and the mean of these four counts was each time calculated for each cue and each colony (Table 1, 2, 3, 4, upper part). This allowed determination if the ants foraged and consequently saw the presented cues.

Table 2. Experiment 2: Ants' discrimination between a cue with one black circle and a fully white cue

\begin{tabular}{|c|c|c|c|c|c|c|}
\hline \multirow{3}{*}{ Training } & \multicolumn{6}{|c|}{ Mean $n^{\circ}$ of ants near the cues } \\
\hline & \multirow{2}{*}{\multicolumn{2}{|c|}{$\square+$ food }} & & \multicolumn{3}{|c|}{ Colony B } \\
\hline & & & & \multicolumn{2}{|c|}{+ food } & $\square$ \\
\hline Day 1 & \multicolumn{2}{|c|}{4.25} & 1.50 & \multicolumn{2}{|c|}{2.00} & 1.00 \\
\hline Day 2 & \multicolumn{2}{|c|}{3.75} & 1.25 & \multicolumn{2}{|c|}{3.25} & 0.75 \\
\hline Day 3 & 3.50 & & 1.00 & & & 1.25 \\
\hline \multicolumn{7}{|c|}{ Cues removed } \\
\hline \multirow{3}{*}{ Testing } & \multicolumn{6}{|c|}{ Mean $n^{\circ}$ of ants near the cues and $\%$ of correct responses } \\
\hline & \multicolumn{3}{|c|}{ Colony A } & \multicolumn{3}{|c|}{ Colony B } \\
\hline & $\square$ & & $\%$ & & $\square$ & $\%$ \\
\hline 24 hours & 1.15 & 0.75 & 60.5 & 1.75 & 0.70 & 71.4 \\
\hline 48 hours & 3.10 & 1.25 & 71.3 & 2.80 & 0.85 & 76.7 \\
\hline 72 hours & 1.95 & 0.80 & 70.9 & 1.55 & 0.45 & 77.5 \\
\hline \multicolumn{7}{|c|}{ Cues removed } \\
\hline 24 hours & 2.10 & 1.15 & 64.6 & 1.35 & 0.75 & 64.3 \\
\hline 48 hours & 2.80 & 2.40 & 53.8 & 1.45 & 1.05 & 58.0 \\
\hline 72 hours & 1.90 & 2.20 & 46.3 & 1.20 & 0.80 & 60.0 \\
\hline
\end{tabular}

Same numbers of counts as for Table 1. Statistics are given in the text. The ants could discriminate the two presented cues though less than those previously presented (see Table 1).

Table 3. Experiment 3: Ants' discrimination between a cue with one black square and 'nothing' (i.e. no cue, zero cue)

\begin{tabular}{|c|c|c|c|c|c|c|}
\hline \multirow{3}{*}{ Training } & \multicolumn{6}{|c|}{ Mean $n^{\circ}$ of ants near the cue or the 'nothing' site (= the zero) } \\
\hline & \multicolumn{3}{|c|}{ Colony A } & \multicolumn{3}{|c|}{ Colony B } \\
\hline & \multicolumn{2}{|c|}{]+ food } & no cue & \multicolumn{2}{|c|}{ no cue + food } & $\square$ \\
\hline Day 1 & \multicolumn{2}{|c|}{3.75} & 2.25 & \multicolumn{2}{|c|}{3.25} & 2.50 \\
\hline Day 2 & \multicolumn{2}{|c|}{4.25} & 2.50 & \multicolumn{2}{|c|}{2.00} & 2.25 \\
\hline Day 3 & \multicolumn{2}{|c|}{2.50} & 2.00 & \multicolumn{2}{|c|}{2.50} & 2.25 \\
\hline \multicolumn{7}{|c|}{ Cues removed } \\
\hline \multirow{3}{*}{ Testing } & \multicolumn{6}{|c|}{ Mean $n^{\circ}$ of ants near the cues and the zero and $\%$ of correct responses } \\
\hline & \multicolumn{3}{|c|}{ Colony A } & \multicolumn{3}{|c|}{ Colony B } \\
\hline & & no cue & $\%$ & no cue & $\square$ & $\%$ \\
\hline 24 hours & 1.15 & 0.90 & 56.1 & 1.25 & 0.90 & 58.1 \\
\hline 48 hours & 2.50 & 0.90 & 73.5 & 3.20 & 2.15 & 59.8 \\
\hline 72 hours & 2.90 & 0.40 & 87.9 & 2.80 & 1.25 & 69.1 \\
\hline \multicolumn{7}{|c|}{ Cues removed } \\
\hline 24 hours & 2.35 & 0.70 & 77.0 & 1.65 & 0.75 & 68.7 \\
\hline 48 hours & 1.90 & 0.55 & 77.5 & 3.05 & 2.30 & 57.0 \\
\hline 72 hours & 2.95 & 2.10 & 58.4 & 1.80 & 1.75 & 50.7 \\
\hline
\end{tabular}

Same numbers of counts as for Table 1. Statistics are given in the text. The ants distinguished the black square from the absence of a cue and did so better when the reward was associated with the cue (stand + paper + square) than when it was associated with its absence. 
Table 4. Experiment 4: Ants' discrimination between a cue with one black square and 'nothing' (i.e. no cue, zero cue), using two novel colonies

\begin{tabular}{|c|c|c|c|c|c|c|c|}
\hline \multirow{3}{*}{ Training } & \multicolumn{7}{|c|}{ Mean $n^{\circ}$ of ants near the cue or the 'nothing' site (= the zero) } \\
\hline & \multicolumn{4}{|c|}{ Colony C } & \multicolumn{3}{|c|}{ Colony D } \\
\hline & \multicolumn{2}{|r|}{+ food } & & no cue & \multicolumn{2}{|c|}{ no cue + food } & $\square$ \\
\hline Day 1 & \multicolumn{2}{|r|}{2.25} & & 2.50 & \multicolumn{2}{|c|}{3.00} & 3.00 \\
\hline Day 2 & \multicolumn{2}{|r|}{3.75} & & 1.75 & \multicolumn{2}{|c|}{4.00} & 1.75 \\
\hline Day 3 & \multicolumn{2}{|r|}{3.00} & & 2.50 & \multicolumn{2}{|c|}{6.50} & 2.50 \\
\hline Day 4 & \multicolumn{2}{|r|}{3.00} & & 2.75 & \multicolumn{2}{|c|}{3.25} & 3.25 \\
\hline \multicolumn{8}{|c|}{ Cues removed } \\
\hline \multirow{3}{*}{ Testing } & \multicolumn{7}{|c|}{ Mean $n^{\circ}$ of ants near the cues and the zero and \% of correct responses } \\
\hline & \multicolumn{4}{|c|}{ Colony C } & \multicolumn{3}{|c|}{ Colony D } \\
\hline & & & no cue & $\%$ & no cue & $\square$ & $\%$ \\
\hline 24 hours & 2.25 & & 0.70 & 76.3 & 1.40 & 0.90 & 60.9 \\
\hline 48 hours & 2.40 & & 0.65 & 78.7 & 1.90 & 0.95 & 66.7 \\
\hline 72 hours & 4.10 & & 0.95 & 81.2 & 2.00 & 0.75 & 72.7 \\
\hline 96 hours & 2.00 & & 0.45 & 81.6 & 1.85 & 0.85 & 68.5 \\
\hline \multicolumn{8}{|c|}{ Cues removed } \\
\hline 24 hours & 2.80 & & 0.75 & 78.9 & 2.50 & 1.35 & 64.9 \\
\hline 48 hours & 3.20 & & 1.15 & 73.5 & 1.85 & 1.00 & 64.9 \\
\hline 72 hours & 1.60 & & 0.60 & 72.7 & 1.30 & 0.85 & 60.4 \\
\hline 96 hours & 1.75 & & 0.80 & 68.6 & 1.15 & 1.25 & 47.9 \\
\hline
\end{tabular}

Same numbers of counts as for Table 1. Statistics are given in the text. Qualitatively as for the experiment 3, the ants distinguished the black square from the absence of a cue, the best when the reward was associated with the cue (stand + paper + square) than when it was associated with the absence of cue.

\subsection{Testing the Ants}

For each four performed experiments, a test was made after 24, 48, 72 as well as 96 for experiment 4, hours of training, and 24, 48, 72 as well as 96 for experiment 4, hours after the cues removal, in order to assess the ants' operant conditioning acquisition then loss, and through this process, the ants' discrimination between the two cues. This is schematized in Figure 2, lower part, and photos of the ants' reaction are shown in Figure 3. A short and light grey line was pencil drawn at the place of the 'zero' cue to help with counting the ants at precise location (Figure 3, E, F, G, H).

To make a test, 20 ants of each experimental colony were transferred into a tray (a distinct tray for each colony) $(30 \mathrm{~cm} \times 15 \mathrm{~cm} \times 4 \mathrm{~cm})$ into which have been placed the two kinds of cues provided to the ants during their training session. To avoid making counting errors, the two kinds of cues were always similarly set in the trays, but the trays were randomly differently oriented over the successive tests. The ants approaching each kind of cue were then counted 20 times in the course of 10 minutes (i.e. a count each 30 seconds), and the mean of these counts was established for each kind of cue and each colony. From these means, the proportion of ants of each colony moving to the cue associated with food during the training session could be calculated (Tables 1, 2, 3, 4, lower part). 


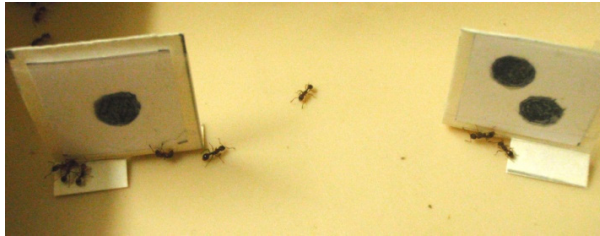

A

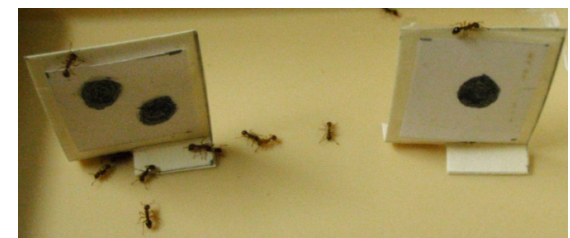

$\mathbf{B}$

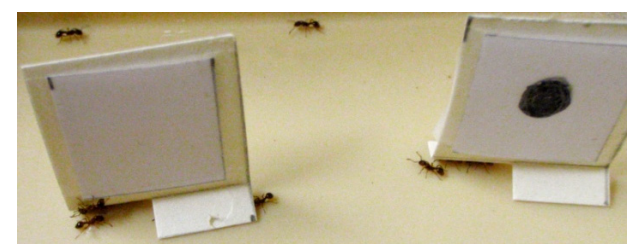

C

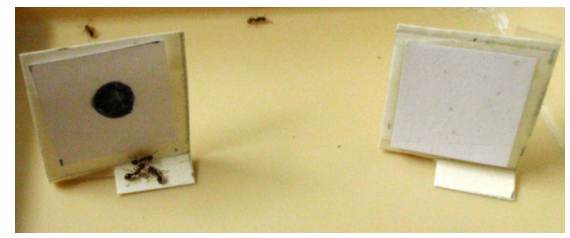

D

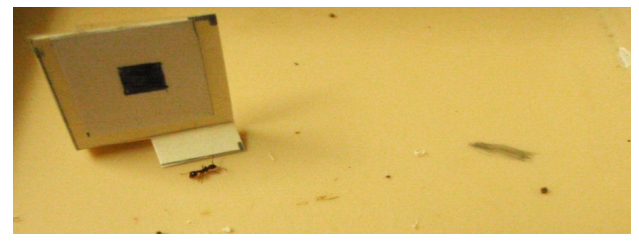

$\mathbf{E}$

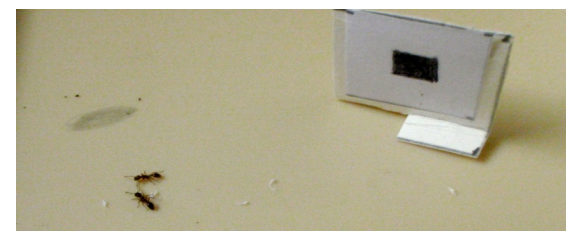

$\mathbf{F}$

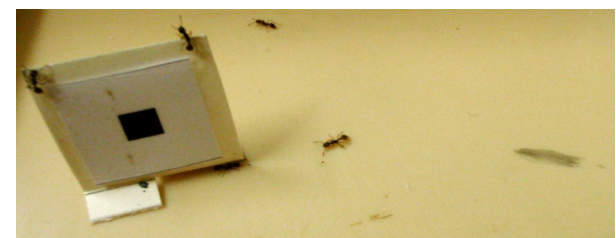

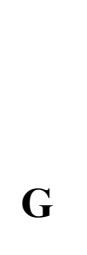

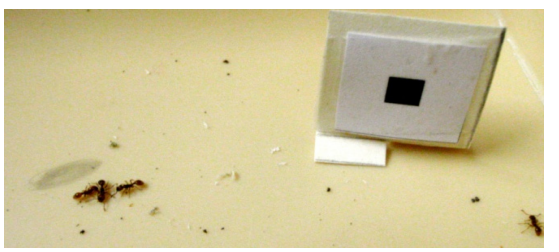

$\mathbf{H}$

Figure 3. Sample photos of the experiments

A: experiment 1, colony A: the ants have moved towards the 'one black circle' to which they have been trained. B: experiment 1, colony B: the ants have moved towards the 'two black circles' to which they have been trained. C: experiment 2, colony A: three ants having come in front of the white paper (the cue associated with food during training) and one ant having approached the white paper with a black circle (the cue not associated to food during training). D: experiment 2, colony B: three ants just in front of the cue with one black circle to which they have been trained. E: experiment 3, colony A: an ant approaching the cue associated with food during training. F: experiment 3, colony B: two ants having moved to and staying near the missing cue, i.e. the absence of cue to which they have been trained for 24 hours. G: experiment 4, colony C: four ants reacting to the cue with a black square associated with food during training. H: experiment 4 , colony D: three ants reacting to 'the absence of cue' associated with food during training.

\subsection{Statistical Analysis}

The numbers of ants obtained during the training sessions did not require any statistical analysis. As for the testing session, the statistical method was identical for each of the four experiments, but more statistical tests were performed for experiments 3 and 4 than for experiments 1 and 2 . The numbers used for the statistical tests can easily be calculated from the means of 20 counts, given in the tables 1-4. For each statistically analyzed test, the numbers of ants of colony A, of colony B, and/or the total of these two numbers counted near each kind of cue (that associated with food and the other one) were compared to the numbers expected if the ants went randomly near each kind of cue, using the non-parametric goodness of fit test (Siegel \& Castellan, 1989), 0.05 being used as limit of statistical significance.

\section{Results}

\subsection{Experiment 1}

Numerical results are given in Table 1. During training, the ants foraged enough to come near the two presented cues (upper part of the table). When tested in front of these cues, the ants progressively approached more often the cue associated with food than the other cue (Figure $3 \mathrm{~A}, \mathrm{~B}$ ), reaching a conditioning score of $68.1 \%, 79.8 \%$, $75.0 \%$ (colony A) and $74.7 \%, 76.4 \%, 90.0 \%$ (colony B) after 24, 48 and 72 hours respectively. The total number of ants counted in front of the cue associated with food (180) and in front of the other cue (34) after 72 hours of 
training highly differed from the numbers expected if the ants randomly went towards each kind of cue (107) $\left(\chi^{2}\right.$ $=99.60, \mathrm{df}=1, \mathrm{P}<0.001)$. Considered separately, the numbers obtained for colony A as well as those obtained for colony B differed from the expected random ones: colony A: 63 and $21 v s 42$ and $42 ; \chi^{2}=21.00, \mathrm{df}=1, \mathrm{P}<$ 0.001; colony B: 117 and 13 vs 65 and $65 ; \chi^{2}=83.20, \mathrm{df}=1, \mathrm{P}<0.001$. This showed that the ants could easily discriminate one black circle from two black ones. After removal of the two cues from the ants' foraging area, the ants progressively lost their conditioning. They reached a conditioning score of $52.3 \%$ (colony A) and $46.9 \%$ (colony B) 72 hours after having no longer seen the cues. The total number of ants counted during training in front of one and the other kind of cue then equaled 38 and 38 respectively. The ants have thus fully lost their conditioning in 72 hours, and the next experiment could thus be then undertaken.

\subsection{Experiment 2}

Numerical results are detailed in Table 2. During training, ants were always seen near the two presented cues (upper part of the Table). In the course of the three testing sessions, the ants came near the cue associated with food progressively more often than near the other cue (Figure $3 \mathrm{C}, \mathrm{D}$ ), reaching a conditioning score of $60.5 \%$, $71.3 \%, 70.9 \%$ (colony A) and 71.4\%, 76.7\%, 77.5\% (colony B) after 24, 48, and 72 hours respectively. The total number of ants counted after 72 hours of training in front of each kind of cue (70 and 25) statistically differed from those expected if the ants randomly visited each kind of cue (47.5) $\left(\chi^{2}=21.10, \mathrm{df}=1, \mathrm{P}<0.001\right)$. Considered separately, the numbers obtained for colony A as well as those obtained for colony B differed from the expected random ones: colony A: 39 and $16 v s 27.5$ and 27.5; $\chi^{2}=10.47, \mathrm{df}=1,0.001<\mathrm{P}<0.01$; colony B: 31 and 9 vs 20 and $20 ; \chi^{2}=12.10, \mathrm{df}=1, \mathrm{P}<0.001$. This showed that the ants could discriminate a paper with a black circle from a paper with no black circle. A comparison of Tables 1 and 2 shows that the ants better discriminated one from two black circles than one circle from a white paper (compare also the $\chi^{2}$ values given here to those of the analysis made for experiment 1).

Furthermore, during this experiment 2, the ants soon lost their conditioning after the two cues were removed. After 24 hours, they presented a conditioning score of only $64.6 \%$ (colony A) and $64.3 \%$ (colony B), but this result was still significant (counted ants: 69, 38; expected random numbers: 53.5, 53.5; $\chi^{2}=8.41$, $\mathrm{df}=1,0.001<$ $\mathrm{P}<0.01$ ). Forty-eight hours after the removal of the cues, the ants did not go significantly towards the cue associated with food. They exhibited a conditioning score of $53.8 \%$ (colony A) and $58.0 \%$ (colony B). The total number of ants counted in front of the cue associated with food and in front of the other cue (82 and 69 respectively) did not statistically differ from those resulting from a random moving of the ants (75.5 and 75.5) $\left(\chi^{2}=0.95, \mathrm{df}=1,0.30<\mathrm{P}<0.50\right)$. Thus, in 48 hours, the ants nearly lost their conditioning, what was sooner than when trained in front of one and two black circles (see the experiment 1). Seventy-two hours after the removal of the cues, during testing, the ants moved equally towards the two kinds of cue (conditioning score of colony $\mathrm{A}=46.3 \%$, of colony $\mathrm{B}=60.0 \%$ ). The total numbers of counted ants near the two kinds of cue ( 62 and $60)$ did not differ from the expected random ones $(61$ and 61$)\left(\chi^{2}=0.032, \mathrm{df}=1,0.80<\mathrm{P}<0.90\right)$. The ants have thus fully lost their conditioning and the third experiment could be attempted (see below).

\subsection{Experiment 3}

Numerical results are detailed in Table 3. During the training session, the ants visited the site with the reward as well as that without a reward just like they visited the two sites during the training session of the experiment 1 and 2 (Tables 1, 2, 3, upper parts). When tested after 24 hours of training, the ants showed a slight degree of learning, the ants of colony A reaching a score of $56.1 \%$ and those of colony B a score of $58.1 \%$ (Figure $3 \mathrm{E}, \mathrm{F}$ ). After 48 hours of training, these scores had increased up to $73.5 \%$ for colony A, but reached only $59.8 \%$ for colony B. A difference appeared thus between the two colonies, i.e. the one having the black square associated with food and the other having no cue associated with food. After 72 hours of training, the ants of colony A presented a conditioning score of $87.9 \%$ and those of colony B, a score of $69.1 \%$, both scores being statistically significant. The numbers of ants of colony A counted near the black square and the 'missing cue' (58 and 8 respectively) differed from the random expected ones $(25$ and 25$)\left(\chi^{2}=37.88, \mathrm{df}=1, \mathrm{P}<0.001\right)$. The numbers of ants of colony B counted in front of 'nothing' and of the black square (56 and 25 respectively) also differed significantly from the random expected ones (40.5 and 40.5) though to a lower extend: $\chi^{2}=11.12, \mathrm{df}=1, \mathrm{P}<$ 0.001 . Of course, the total numbers of ants counted near the cue associated with food and near the other cue (114 and 33 respectively) highly differed from the random expected ones (73.5 and 73.5): $\chi^{2}=43.54, \mathrm{df}=1, \mathrm{P}<$ 0.001 . The ants could thus discriminate an element and the absence of an element, and they did so better when the reward was associated with an element than when it was associated with an absence of element. However, even in the latter case, the ants succeeded in discriminating the absence of a cue, revealing thus their understanding of the non existence of something. More explanation is given in the Discussion section. 
After this third test, the cues were removed from the ants' foraging area, and the insects progressively lost their conditioning. After 24 hours, ants of colony A presented a significant conditioning score of $77.0 \%$ (47 and 15 counted ants $v s 30.5$ and 30.5 random expected ones; $\chi^{2}=16.79$, $\mathrm{df}=1, \mathrm{P}<0.001$ ), and ants of colony $\mathrm{B}$ presented the conditioning score of $68.7 \%$, which was also though less significant (33 and 15 counted ants vs 24 and 24 random expected ones; $\left.\chi^{2}=6.76, \mathrm{df}=1,0.001<\mathrm{P}<0.01\right)$. The total numbers of counted ants ( 80 and 29) of course statistically differed from the expected random numbers (54.5 and 54.5) $\left(\chi^{2}=22.93, \mathrm{df}=1, \mathrm{P}<0.001\right)$. After 48 hours, the ants of colony A still presented a conditioning score of $77.6 \%$, what was statistically significant ( 38 and 11 counted ants $v s 24.5$ and 24.5 expected random ones; $\chi^{2}=13.80$, $\mathrm{df}=1, \mathrm{P}<0.001$ ), while ants of colony B presented a conditioning score of $57.0 \%$, that was under the limit of significance $(61$ and 46 counted ants $v 553.5$ and 53.5 expected random ones; $\chi^{2}=1.85, \mathrm{df}=1,0.10<\mathrm{P}<0.20$ ). The total numbers of counted ants for the two colonies ( 99 and 57) still differed from the random expected ones ( 78 and $78, \chi^{2}=11.30$, $\mathrm{df}=1, \mathrm{P}<0.001)$. After that, the ants went on losing their conditioning. Seventy-two hours after the cues removal, ants of colony A had a conditioning score of 58.4\% (a not significant performance: 59 and 42 counted ants $v s 50.5$ and 50.5 expected random ones; $\chi^{2}=2.53 \mathrm{df}=1,0.10<\mathrm{P}<0.20$ ), and ants of colony $\mathrm{B}$ a conditioning score of $50.7 \%$ (also a not significant performance: 36 and 35 counted ants vs 35.5 and 35.5 random expected ones). The total numbers of ants counted for the two colonies (95 and 77) also did not differ from the expected random ones $(86$ and 86$)\left(\chi^{2}=1.88, \mathrm{df}=1,0.10<\mathrm{P}<0.20\right)$. The ants thus entirely lost their learning in about 60-70 hours. The ants having been trained with the 'nothing' associated with food lost their conditioning more rapidly than those which had the cue (the black square) associated with food. In other words, the ants learned poorly and quickly forgot the non existence of an item, while they well learned and remembered during a longer time an existing item.

\subsection{Experiment 4}

The experiment 3 was reproduced on two never used colonies (C and D) in order to check the results above. Numerical results are given in Table 4. During training, ants of colonies C and D foraged as usually and approached the two sites, i.e. that with the cue (a black square, associated with food for colony C) and that with no cue (associated with food for colony D) (Table 4, upper part). The ants were trained during four instead of three days. After 24 hours of training, the ants of colony $\mathrm{C}$ revealed a score of $76.3 \%$ (a significant score: 45 and 14 counted ants $v s 29.5$ and 29.5 expected random ones; $\chi^{2}=15.26, \mathrm{df}=1, \mathrm{P}<0.001$ ), while those of colony $\mathrm{D}$ reached only $60.9 \%$ of conditioning (a not significant score: 27 and 18 counted ants $v s 22.5$ and 22.5 expected random ones; $\chi^{2}=1.42, \mathrm{df}=1,0.20<\mathrm{P}<0.30$ ). This first test is illustrated in Figure $3 \mathrm{G}, \mathrm{H}$. The total numbers of ants counted for the two colonies (72 and 32) statistically differed from the expected ones (52 and 52) $\left(\chi^{2}=\right.$ $15.38, \mathrm{df}=1, \mathrm{P}<0.001$ ). Twenty-four more hours later, the ants of colony $\mathrm{C}$ had reached a score of $78.7 \%$ (that was significant: 48 and 13 counted ants $v s 30.5$ and 30.5 expected random ones; $\chi^{2}=18.95, \mathrm{df}=1, \mathrm{P}<0.001$ ), and the ants of colony $\mathrm{D}$ a score of $66.7 \%$ (what was slightly significant: 38 and 19 counted ants $v s 28.5$ and 28.5 expected random ones; $\chi^{2}=5.68, \mathrm{df}=1,0.01<\mathrm{P}<0.02$ ). The ants with the absence of a cue associated with food acquired their conditioning more slowly than those having the cue associated with the reward. The total numbers of ants counted for the two colonies (86 and 32) statistically differed from the expected random ones (59 and 59) $\left(\chi^{2}=24.71, \mathrm{df}=1, \mathrm{P}<0.001\right)$. After 72 hours of training, the ants showed higher conditioning scores, i.e. the ants of colony $\mathrm{C}$ a score of $81.2 \%$ (what was significant: 82 and 19 counted ants $v s 50.0$ and 50.5 expected random ones; $\chi^{2}=38.06, \mathrm{df}=1, \mathrm{P}<0.001$ ), and the ants of colony $\mathrm{D}$, a score of $72.7 \%$ (what was somewhat less significant: 40 and 15 counted ants $v s 27.5$ and 27.5 expected random one; $\chi^{2}=10.47, \mathrm{df}=1$, $0.001 \sim \mathrm{P}<0.01)$. The total numbers of counted ants (120 and 34) statistically differed from the random expected numbers (77 and 77) $\left(\chi^{2}=48.02, \mathrm{df}=1, \mathrm{P}<0.001\right)$.

The last test made after 96 hours of training revealed that the ants' conditioning no longer increased but kept the same optimum levels as after 72 hours of training or even a somewhat lower level. Indeed, the ants of colony $\mathrm{C}$ had a score of $81.6 \%$ (40 and 9 counted ants $v s 24.5$ and 24.5 expected random ones; $\chi^{2}=18.38, \mathrm{df}=1, \mathrm{P}<$ 0.001 ) while the ants of colony D had a score of $68.5 \%$ (37 and 17 counted ants $v s 27$ and 27 expected random ones; $\left.\chi^{2}=7.40, \mathrm{df}=1,0.001<\mathrm{P}<0.01\right)$. The counted ants for colonies $\mathrm{C}+\mathrm{D}$ equaled 77 and 26 , which statistically differed from the random expected numbers, 51.5 and $51.5\left(\chi^{2}=24.27, \mathrm{df}=1, \mathrm{P}<0.001\right)$. With the results being similar to those of the experiment 3, it can be concluded that the M. sabuleti ants can comprehend the non existence of a cue, and that they did so at best when the reward was associated with the cue. However, even when the reward was associated with the absence of a cue, the ants could also comprehend such an absence.

After the cues were removed from the ants' foraging area, the ants lost their conditioning. After 24 hours, the ants of colony $\mathrm{C}$ had a conditioning score of 78.9\% (which was still significant: 56 and 15 counted ants $v s 35.5$ and 35.5 expected random ones; $\left.\chi^{2}=22.54, \mathrm{df}=1, \mathrm{P}<0.001\right)$ and the ants of colony $\mathrm{D}$ a score of $64.9 \%$ (a 
somewhat less significant result: 50 and 27 counted ants $v s 38.5$ and 38.5 randomly expected; $\chi^{2}=6.28, \mathrm{df}=1$, $0.01 \sim \mathrm{P}<0.02)$. The results corresponding to colonies $\mathrm{C}+\mathrm{D}(106$ and 42 counted ants $)$ still differed from the expected random ones $(74$ and 74$)\left(\chi^{2}=27.67, \mathrm{df}=1, \mathrm{P}<0.001\right)$. Forty-eight hours after the cues were removed, the ants of colony $\mathrm{C}$ presented a significant score of $73.5 \%$ (64 and 23 counted ants $v s 43.5$ and 43.5 expected random ones; $\left.\chi^{2}=18.18, \mathrm{df}=1, \mathrm{P}<0.001\right)$, and those of colony $\mathrm{D}$ a slightly significant score of $64.9 \%$ (37 and 20 counted ants $v$ s 28.5 and $\left.28.5 ; \chi^{2}=4.48, \mathrm{df}=1,0.02<\mathrm{P}<0.05\right)$. The counted numbers of ants of colonies $\mathrm{C}+\mathrm{D}\left(101\right.$ and 43) still differed from the expected random ones (72 and 72) $\left(\chi^{2}=23.36, \mathrm{df}=1, \mathrm{P}<0.001\right)$. Seventy-two hours after the cues removal, ants of colony $\mathrm{C}$ still had a significant conditioning score of $72.7 \%$ ( 32 and 12 counted ants $v s 22$ and 22 expected random ones; $\chi^{2}=9.09, \mathrm{df}=1,0.001<\mathrm{P}<0.01$ ), and ants of colony $\mathrm{D}$ a non significant score of $60.4 \%$ ( 26 and 17 counted ants $v s 21.5$ and 21.5 expected random ones; $\chi^{2}=$ 1.48 , $\mathrm{df}=1,0.30<\mathrm{P}<0.50)$. The total numbers of ants obtained for the two colonies (58 and 28) slightly differed from expected random ones (43.5 and 43.5) $\left(\chi^{2}=9.01, \mathrm{df}=1,0.001<\mathrm{P}<0.01\right)$. Comparing the results obtained in the course of the loss of conditioning observed during the experiments 3 and 4 allowed stating that conditioning the ants during 96 hours instead of 72 hours did not increase the final score but improved the ants' long-term memory. Ninety-six hours after the cues removal, the ants of colony $\mathrm{C}$ had a slightly significant score of $68.6 \%$ (35 and 16 counted ants $v s 25.5$ and 25.5 expected random ones; $\chi^{2}=6.35$, df $=1,0.01<\mathrm{P}<0.02$ ), and those of colony D a not at all significant score of $47.9 \%$ (23 and 25 counted ants $v s 24$ and 24 expected random ones; $\chi^{2}=0.08, \mathrm{df}=1,0.70<\mathrm{P}<0.80$ ). The total numbers of counted ants (58 and 41) no longer differed from the random expected ones (50 and 49) $\left(\chi^{2}=2.58, \mathrm{df}=1,0.10<\mathrm{P}<0.20\right)$. The experiment thus ended.

\section{Discussions}

Aiming to examine if ants could be at the first stage of the comprehension of the notion of zero, and working on the species M. sabuleti, we found that these workers 1) could easily distinguish one black circle from two black ones, 2) could, although less well, discriminate one black circle from a white paper, 3) could, also less well, distinguish a black square from the absence of an element, the latter observation having been repeated on two never used colonies. During these experiments, the ant $M$. sabuleti could thus perceive the absence of a cue at a given site. They exhibited a very basic, concrete, sensory perceptible, notion of a 'zero'. In nature, of course, they can perceive the absence of previously present food, but they might also perceive the absence of a previously present visual cue, olfactory element, or a queen, for example. This can lead to a future experimental work: looking if ants could perceive a 'null existence' when trained with a diffuser provided with an odor and an empty diffuser associated with a reward. In addition, our work pointed out that extending the conditioning did not lead to better scores but improved the individuals' long-term memory.

Having the comprehension of 'zero' is not common in the Animal Kingdom. Even among the humans, this ability does not always exist.

Nieder (2016) explored human history and human's neurophysiology, and proposed that the emergence of the notion of zero passes through four stages before becoming a fully abstract notion (nothing perceptibly to the senses, categorically different from something, quantitatively empty, and finally the 'number', the symbol for an abstract notion of zero). We might cautiously propose that the ant species we studied may possess the first stage of the notion of zero, i.e. the one perceptible to the senses though yet requiring some cognition. Humans acquire the numbers $(1,2,3, \ldots)$ and the zero $(0)$ notions sooner or later in the course of their life, the concept of the number zero being the last acquired (Fuson, 1988), maybe according to the process proposed by Nieder (2016).

Biro and Matsuzawa (2001) observed that the chimpanzee (Pan troglodytes) could use numerical symbols (at a cardinal then an ordinal level) and seemed to approach the zero concept. In fact, the chimpanzee often confounded the zero with the number 1; it considered the zero as being the lower number and it never abstractly thought of the zero. We might suggest the hypothesis that these monkeys may acquire, through artificial or natural experiences, the first, second and maybe third stages of the zero comprehension. Working on 11 pet dogs, West and Young (2002) showed that these mammals, finally and unexpectedly, anticipated the outcome of very simple calculations, presenting thus a very rudimentary ability to count (e.g. $1+1=2)$. However, the authors did not attempt to investigate their dogs' comprehension of the zero concept.

After initial work on the subject (Pepperberg, 1988), and consequent research (Pepperberg \& Gordon, 2005; Pepperberg, 2006) these authors studied in two steps the comprehension of numbers and of the notion of zero in a parrot, Psittacus erithacus. The experiments done in 2005 proved that this bird could, with an accuracy of $80 \%$, comprehend the numbers 2 to 6 , as well as the absence of any quantity, hence the notion of zero. The experiments published in 2006 confirmed the same parrot's abilities in adding (from 'nothing' to 6), and defined 
its limits as for the relation between "none" and the concept of zero. We might presume that the parrot possesses a more basic notion of zero than the fourth and even the third stage of such a notion. The parrot's ability may be comparable to the nonhuman primates' and the young children's one (i.e. difficulties with a concrete notion of zero, no abstract notion of zero).

An experimental work was recently conducted on the subject of the zero concept on the bee Apis mellifera (Howard, Avarguès-Weber, Garcia, Greentree, \& Dyer, 2018). The bees were trained to discriminate numbers 1 to 6 , then an empty set from these numbers 1 to 6 . The bees succeeded in completing the first task: they thus have the notion of 'what is lower'. They also correctly chose a cue with no element versus a cue with one element. They can thus perceive the empty set as belonging to the lower end of a numerical continuum. The most basic result of this experiment on bees is comparable to that of our second experiment: the ants could (but weakly) discriminate a white paper with no black circle from a white paper with one black circle. However, a white paper is a cue; it is not an absence, a 'nothing'. We here went a step further and looked if ants could distinguish the absence of a cue, i.e. 'nothing'. Effectively, through differential operant conditioning, they succeeded in doing so, and did so better when the cue (the presence) was associated with the reward than when the 'nothing' (the absence) was associated with the reward. This is a very basic notion of zero, a concrete notion perceptible to senses.

The present study of ants being at the first stage of a comprehension of the zero concept is an extension of our previous research the aim of which was to define the subtle limit of the ants' cognitive abilities. We have already shown that ants, at least $M$. sabuleti, can solve some problems, correctly react in new situations, cannot use sensu stricto tools, can acquire serial recognition but only if rewarded, and can subsequently exhibit behavior acquired through conditioning (Cammaerts, 2017a, 2017b, 2018; Cammaerts \& Cammaerts, 2018a, 2018b, 2018c). Based on this study, we can add that $M$. sabuleti can acquire through experiences some basic, concrete, notion of the absence, non existence, or null presence of an element, which is the initial step to a notion of zero.

\section{Conclusion}

We conclude that ants can, after adequate experiences, understand the concept of absence, non existence, 'nothingness'. They can thus acquire during their life a concrete notion of the null existence of an element, which is the first, basic, level of the acquisition of the notion of zero (of the understanding of the ' 0 '). This new finding has allowed us to expand our understanding of the ants' cognitive abilities.

\section{Acknowledgements}

We are very grateful to an anonymous referee who considerably improved the writing of our manuscript.

\section{Conflict of interests}

The authors declare that there is no conflict of interests regarding the publication of this paper.

\section{References}

Biro, D., \& Matsuzawa, T. (2001). Use of numerical symbols by the chimpanzee (Pan troglodytes): Cardinals, ordinals, and the introduction of zero. Animal Cognition, 4(3-4), 193-199. Retrieved from https://link.springer.com/article/10.1007/s100710100086

Cammaerts, M. C. (2004). Some characteristics of the visual perception of the ant Myrmica sabuleti. Physiological Entomology, 29, 472-482.

Cammaerts, M. C. (2005). Sensitivity and adaptation of Myrmica sabuleti workers (Hymenoptera: Formicidae) to light. Myrmecologishe Nachrichten, 7, 77-86.

Cammaerts, M. C. (2007a). Colour vision in the ant Myrmica sabuleti MEINERT, 1861 (Hymenoptera: Formicidae). Myrmecological News, 10, 41-50.

Cammaerts, M. C. (2007b). Perspective vision in workers of Myrmica sabuleti MEINERT, 1861 (Hymenoptera: Formicidae). Myrmecological News, 10, 21-26.

Cammaerts, M. C. (2008). Visual discrimination of cues differing as for their number of elements, their shape or their orientation, by the ant Myrmica sabuleti. Biologia, 63, 1169-1180.

Cammaerts, M. C. (2012a). Navigation system of the ant Myrmica rubra (Hymenoptera, Formicidae). Myrmecological News, 16, 111-121.

Cammaerts, M. C. (2012b). The visual perception of the ant Myrmica ruginodis (Hymenoptera-Formicidae). Biologia, 67, 1165-1174. 
Cammaerts, M. C. (2013). Myrmica rubra workers' visual perception (Hymenoptera, Formicidae). Belgian Journal of Zoology, 143, 69-78. Retrieved from https://www.ulb.ac.be/rech/inventaire/unites/pdf/ulb118.pdf

Cammaerts, M. C. (2017a). Ants' ability in solving simple problems. International Journal of Biology, 9(3), 26-37.

Cammaerts, M. C. (2017b). In a novel situation, ants can learn to react as never before - a preliminary study. Journal of Behavior, 2(2), 1011. Retrieved from https://www.jscimedcentral.com/Behavior/

Cammaerts, M. C. (2018). Can Myrmica rubra ants use tools or learn to use them? International Journal of Biology, 10(1), 2018.

Cammaerts, M. C., \& Cammaerts, D. (2009). Light thresholds for colour vision in the workers of the ant Myrmica sabuleti (Hymenoptera: Formicidae). Belgian Journal of Zoology, 138, 40-49.

Cammaerts, M. C., \& Cammaerts, D. (2014). Comparative outlook over three Myrmica species' biotopes and foragers' know-how. Biologia, 69, 1051-1058.

Cammaerts, M. C., \& Cammaerts, R. (2018a). Ants can acquire some serial recognition. International Journal of Biology, 10(2), 23-32.

Cammaerts, M. C., \& Cammaerts, R. (2018b). Can ants apply what they acquired through operant conditioning? International Journal of Biology, 10(4), 16-22.

Cammaerts, M. C., \& Cammaerts, R. (2018c). Myrmica sabuleti workers cannot acquire serial recognition if not rewarded. International Journal of Biology, 10(3), 39-46.

Cammaerts, M. C., \& Rachidi, Z. (2009). Olfactory conditioning and use of visual and odorous elements for movement in the ant Myrmica sabuleti (Hymenoptera, Formicidae). Myrmecological News, 12, 117-127.

Cammaerts, M. C., Rachidi, Z., Beke, S., \& Essaadi, Y. (2012). Use of olfactory and visual cues for traveling by the ant Myrmica ruginodis (Hymenoptera, Formicidae). Myrmecological News, 16, 45-55. Retrieved from https://myrmecologicalnews.org/cms/index.php?option...

Collett, T. S. (1995). Making learning easy: The acquisition of visual information during the orientation flights of social wasps. Journal of Comparative Physiology [A], 177, 737-747.

Dill, M., Wolf, R., \& Heisenberg, M. (1993). Visual pattern recognition in Drosophila involves retinotopic matching. Nature, 365, 751-753. Retrieved from http://psycnet.apa.org/record/1994-16369-001

Fuson, K. C. (1988). Children's Counting and Concepts of Number. New York: Springer-Verlag.

Howard, S. R., Avarguès-Weber, A., Garcia, J. E., Greentree, A. D., \& Dyer, A. G. (2018). Numerical ordering of zero in honey bees. Science, 360(6393), 1124-1126.

Michelot, A. (1966). La notion de zéro. In 'L' enfant' a collection directed by Chateau J. Librairie Philosophique J. Vrin Paris. Retrieved from http://www.vrin.fr/book.php?code=9782711605705

Nieder, A. (2016). Representing something out of nothing: The drawing of zero. Trends in Cognitive Sciences, 20(11), 830-842. Retrieved from https://www.ncbi.nlm.nih.gov/pubmed/27666660

Pearce, J. M. (2008). Animal Learning and Cognition, an Introduction. Hove: Psychology Press. Retrieved from http://www.worldcat.org/title/animal-learning-cognition-an-introduction/oclc/682223995

Pepperberg, I. M. (1988). Comprehension of "absence" by an African Grey parrot: Learning with respect to questions of same/different. Journal of the Experimental Analysis of Behavior, 50, 553-564. Retrieved from https://www.ncbi.nlm.nih.gov/pmc/articles/PMC1338917/

Pepperberg, I. M. (2006). Grey parrot (Psittacus erithacus) numerical abilities: Addition and further experiments on a zero-like concept. Journal of Comparative Psychology, 120(1), 1-11.

Pepperberg, J. M., \& Gordon, J. D. (2005). Number comprehension by a grey parrot (Psittacus erithacus), including a zero-like concept. Journal of Comparative Psychology, 119(2), 197-209.

Rachidi, Z., Cammaerts, M. C., \& Debeir, O. (2008). Morphometric study of the eye of three species of Myrmica (Formicidae). Belgian Journal of Entomology, 10, 81-91.

Siegel, S., \& Castellan, N. J. (1989). Nonparametric statistics for the behavioural sciences. Singapore: McGraw-Hill Book Company. Retrieved from https://www.amazon.com/Sidney-Siegel...Statistics.../B008WDIR6

Srinivasan, M. V. (2010). Honey bees as a model for vision, perception and cognition. Annual Review of Entomology, 55, 267-284. 
Warrant, E. J. (2008). Seeing in the dark: Vision and visual behavior in nocturnal bees and wasps. Journal of Experimental Biology, 211, 1737-1746.

West, R. E., \& Young, R. J. (2002). Do domestic dogs show any evidence of being able to count? Animal Cognition, 5, 183-186.

\section{Copyrights}

Copyright for this article is retained by the author(s), with first publication rights granted to the journal.

This is an open-access article distributed under the terms and conditions of the Creative Commons Attribution license (http://creativecommons.org/licenses/by/4.0/). 